\title{
THE JOURNAL
}

OF

\section{MENTAL SCIENCE}

(THE BRITISH JOURNAL OF PSYCHIATRY)

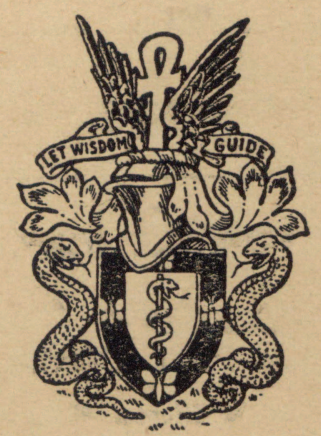

BY AUTHORITY OF

THE ROYAL MEDICO-PSYCHOLOGICAL ASSOCIATION

EDITOR-IN-CHIEF

G. W. T. H. FLEMING

CO-EDITORS

Alexander Walk and P. K. McCowan AND WITH THE ASSISTANCE OF

E. D. Adrian

Sir F. C. Bartlett

S. M. Coleman

C. J. C. Earl

Sir A. Fleming

F. L. Golla
E. G. Holmes

C. J. McCarthy

Alfred Meyer

Lionel S. Penrose

A. A. W. Petrie

E. T. O. Slater

W. Stephenson

LONDON

J. \& A. CHURCHILL, LTD

Published Four times Yearly Twelve Shillings and Sixpence net 


\section{THE JOURNAL OF MENTAL SCIENCE}

Communications on general editorial matters, including MSS. for publication, books for review and other printed matter, and communications regarding the Epitome section, including journals to be abstracted, should be sent to the Editor-in-Chief, Barnwood House, Gloucester.

Communications and inquiries regarding sales should be addressed to the Publishers, Messrs. J. \& A. CHURCHILL, Ltd., 104, Gloucester Place, Portman Square, London, W.1; and those regarding Advertisements to Messrs. S. \& H. FRETWELL, Ltd., 92, Fleet Street, London, E.C.4. Phone : Central 5587/8.

\section{THE ROYAL MEDICO-PSYGHOLOGIGAL ASSOGIATION.}

\section{PUBLICATIONS.}

From Messrs. Adlard \& Son, Ltd., Bartholomew Press, Dorking, Surrey.

Enquiry (History) Form, for use in Mental Hospitals. In three sizes. Prices and specimen forms on application.

Card of Practical Instruction. Prices on application.

From Messrs. J. \& A. Churchill, Ltw., I04 Gloucester Place, W. I

"The Journal of Mental Science." Published four times a year. Price 12/6. Postage extra.

From Messrs. Baillik̀re, Tindall \& Cox, 8 Henrietta Street, W.G. 2

"Handbook for Mental Nurses." 8th edn. In preparation.

"Manual for Mental Deficiency Nurses." r931. Price 6/6 net.

"Occupational Therapy." Addendum to "Handbook." I938. Price 6d.

From the Registrar, Southfield, Shipton Road, York.

"Syllabuses," for the Examinations for the Certificates of Proficiency in Mental Nursing and in Nursing Mental Defectives. Price 2d. each. Postage Id.

"Regulations and Rules for the Nursing Examinations." Revised, 1938. Price gd. each. Postage Id.

6Examination Papers, x928-38," Price 9d. each. Postage Id.

"Regulations for the D.P.M. of the R.M.P.A."

From the Secretary, in Chandos Street, W. I.

The Charter and Bye-Laws of the Association. Price 2/- Postage I $\frac{1}{2} d$. 


\section{pure}

\section{thyroid hormone: practical synthesis}

Recognising the need for a standard form of thyroid medication, capable of being given in precise dosage, Glaxo Laboratories carried through a research project to evolve an entirely new synthesis of the thyroid hormone. Success came in far greater measure than was at first envisaged, for the process ultimately devised has made it possible to manufacture the physiologically active laevo thyroxine free from the inert dextro form.

L-Thyroxine-sodium Glaxo, is the pure crystalline thyroid hormone. By its very nature, it is free from the variations in therapeutic efficacy that may be

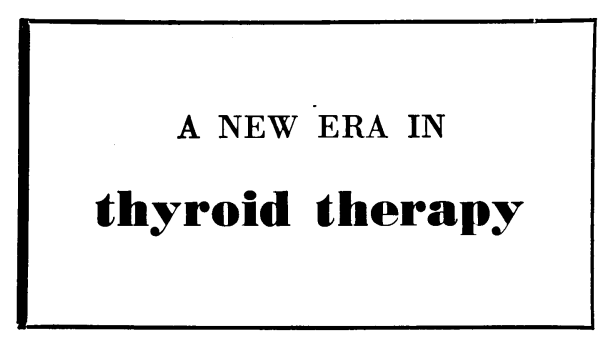
associated with extracts of the thyroid gland. Relative potency is indicated by the fact that about 1 grain of thyroid B.P. may be replaced by $0.1 \mathrm{mg}$. of the Glaxo material.

\section{$\overline{\text { Giviso }}$ \\ L-THYROXINE-SODIUM GIaXO}

TABLETS ( $0.05 \mathrm{mg}$. and $0.1 \mathrm{mg}$ ) : in bottles of 100 and 1,000

GLAXO LABORATORIES LTD., GREENFRD, MIDDLESEX. BYRon 3434 $\boldsymbol{u}$ 


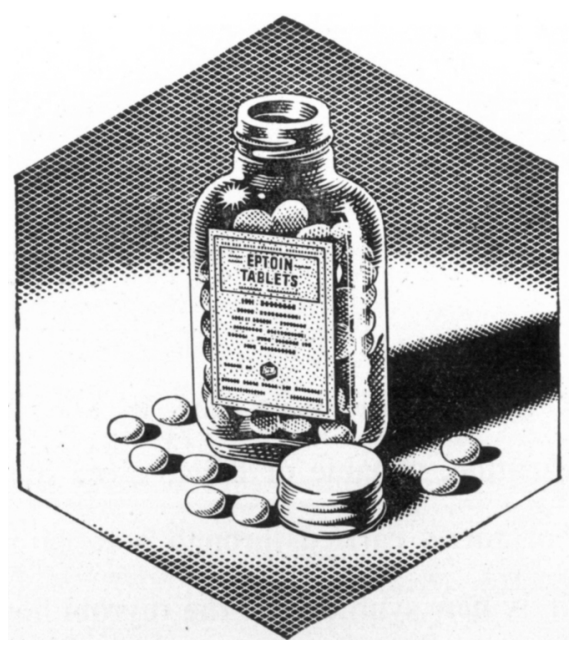

\section{GREATEST}

\section{ANTI-CONVULSANT ACTION, LEAST HYPNOTIC EFFET}

PHENYTOIN SODIUM B.P.-EPTOIN brand is supplied as sugar-coated tablets containing $0.1^{\circ} \mathrm{G}$. for the treatment of epilepsy. It possesses powerful anti-convulsant action and low hypnotic effect. Clinical results indicate that Eptoin greatly reduces the number of seizures in cases which have proved refractory to other forms of therapy.

\section{PHENYTOIN SODIUM}

EPTOIN BRAND

for Epilepsy

Literature and further information from the Medical Dept.

BOOTS PURE DRUG CO. LTD., NOTTINGHAM, ENGLAND 


\section{The PULSAGON Electro-coma Unit}

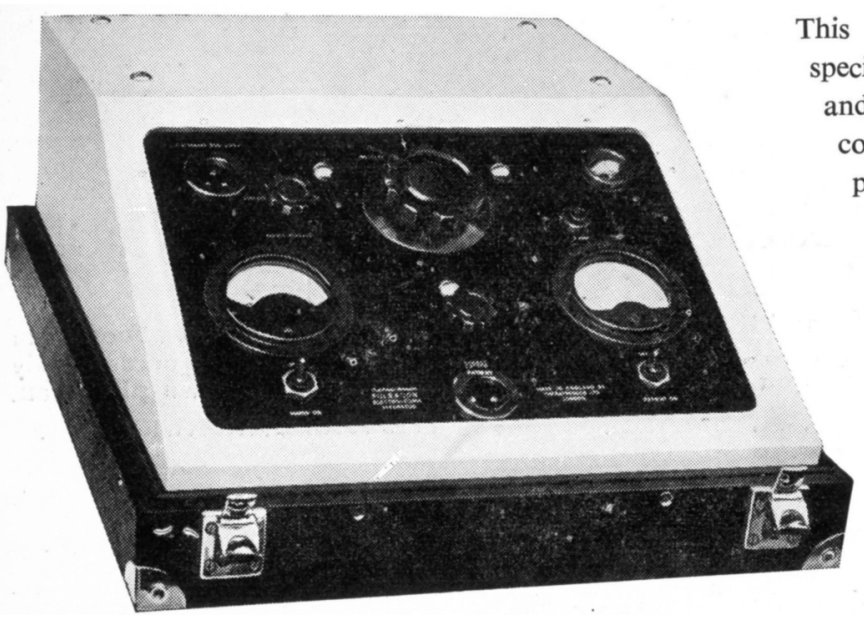

For further details please apply to

THERATRONIGS LTD. (DEPT. B. 4), 6 ARGYLE WALK, LONDON, W.C.1

Telephone: TERminus 2162

\section{ELECTROENCEPHALOGRAPHY}

\section{Editors-in-Chief}

\section{Dr. J. D. N. HILL and GEOFFREY PARR}

The first comprehensive textbook on its subject, with contributions by W. A. COBB, W. GREY WALTER, G. D. GREVILLE, D. WHITTERIDGE and $M$. E. HEPPENSTALL, and with a foreword by Professor E. D. ADRIAN, O.M., F.R.S. An exhaustive yet concise guide for all those using electroencephalography in diagnosis or engaged in electrophysiological research

\section{$£ 3$ 18s. MACDONALD $\&$ Co. (Publishers) Ltd.}




\section{HEIGHAM HALL, NORWICH}

\section{PRIVATE MENTAL HOME}

for Nervous and Mental.illness. All forms of treatment available. Fees from 5 gns. per week upwards, according to requirements. Vacancies occasionally exist at reduced fees on the recommendation of the patient's own physician.
Apply to Dr. J. A. SMALL.
TELEPHONE: NORWICH 20080.

\section{'ECTRON'}

\section{ELECTRO-CONVULSANT APPARATUS}

The ideal portable apparatus for administration of all forms of ECT from A.C. or D.C. mains.

Specially designed to give smooth induction of convulsion, to eliminate fractures.

In use at many leading mental hospitals.

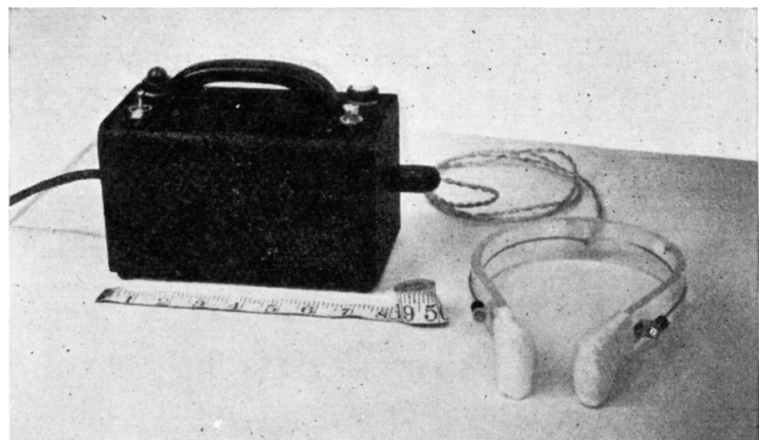

Please write for details of "Intensified ECT" and "Symptomatic Treatment of Hysteria." REEVES ELECTRICAL AND RADIO CO. LTD. REELEK WORKS, BALDOCK, HERTS., ENGLAND

Telegrams: “Reelek" Baldock Telephone: Baldock 154 


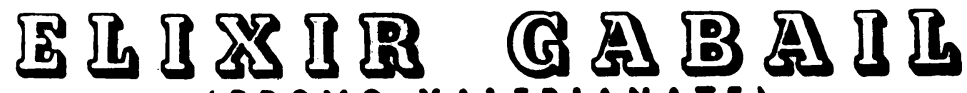
IBROMO-VALERIANATEI

The Ideal Sedative in all Nervous Affections

Elixir Gabail combines the sedative action of Bromide and Chloral Hydrate with the nervine and anti-spasmodic deodorised Valerianate. Pharmaceutically it is as pleasant and palatable as it is efficacious from the therapeutic standpoint, the disagreeable odour and flavour of the Valerian having been completely removed without in any way impairing its therapeutic value.

In Hysteria and Psychasthenia it relieves nervous excitement and produces a calm state of mind that is conducive to rapid recovery. It is also of value in states of temporary emotional excitement, in Hypochondriasis and Melancholia.

Dosage : One tablespoonful in water twice or thrice daily. As a hypnotic: two tablespoonfuls in water at bedtime.

Supplied in bottles of 187 c.c., 16 ozs., and in 40 oz. and 80 oz. Dispensing Packs.

Literature and Samples on request.

\section{The ANGLO-FRENCH DRUG Co. Ltd.}

11-12, Guilford Street, London, W.C. 1 


\section{ADLARD \& SON}

LIMITED

\section{BARTHOLOMEW PRESS}

DORKING - SURREY

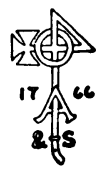

\section{ESTIMATES SUBMITTED PROMPTLY}

FOUNDED IN 1766, the Firm has continued uninterruptedly, and is able to undertake ALL CLASSES OF PRINTING.

The Staff is Specially Trained in the production of all printed matter connected with Private Hospitals and Homes, Medical, Scientific and other Institutions.

\section{ELECTRIC CONVULSION THERAPY}

for treatment of Melancholia, Mental \& Psychiatric Disorders (EDISWAN MODEL)

\section{MEDICAL}

\section{OBSERVATIONS:}

Many thousands of cases have been successfully treated by this method, including sufferers from INVOLUTIONAL MELANCHOLIA, CLIMACTERIC DEPRESSION,RECENT MANIA, ACUTE PSYCHOSES AND OTHER PSYCHIATRIC DISORDERS.

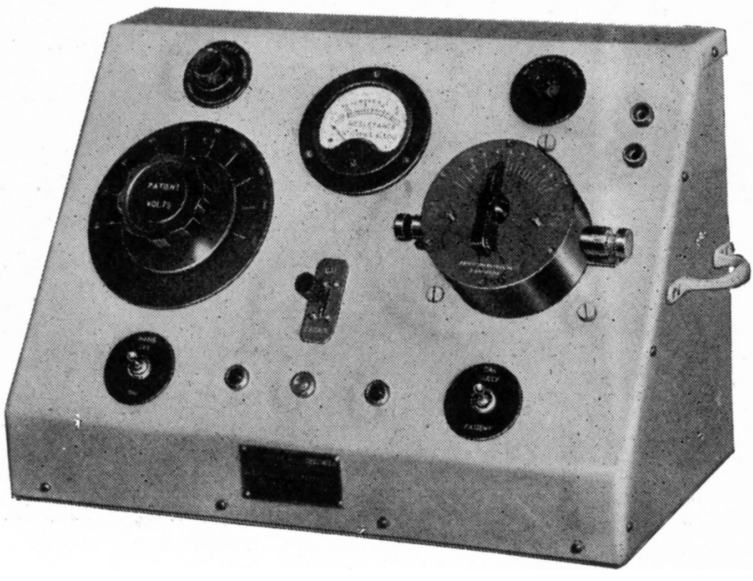

An apparatus constructed to specification of Mr. GREY WALTER. The ideal method for inducing epileptiform seizures. Administration is simple, speedy and effective. Complete amnesia of patient. Apparatus is portable and is in use in more than 250 Hospitals.

Please write for brochure describing technique together with clinical data and blbllography.

\section{COX-CAVENDISH ELECTRICAL CO., LTD.}




\section{BARNWOOD HOUSE}

\section{GLOUCESTER}

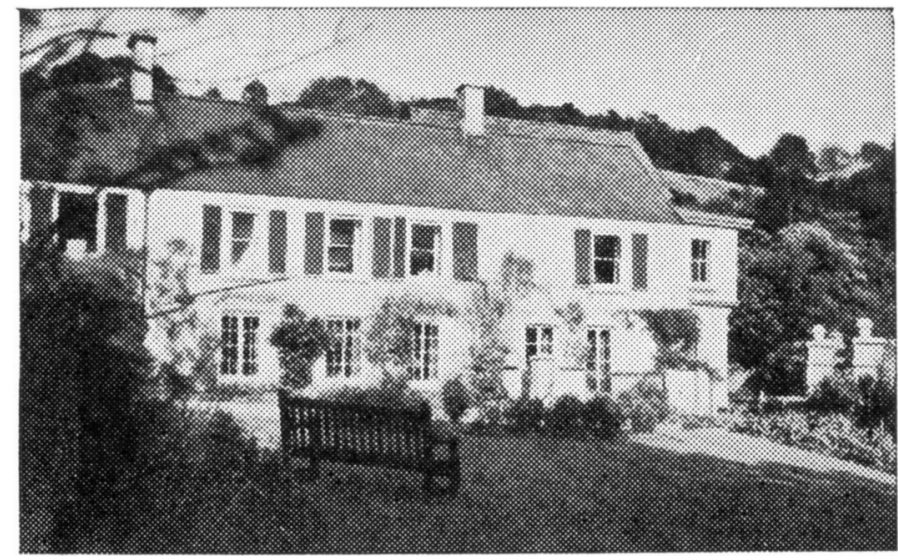

GRICKLEY GOURT-ONE OF THE SEPARATE VILLAS

A REGISTERED HOSPITAL, (outside the

National Health Service) for the GARE and TREATMENT of LADIES and GENTLEMEN suffering from NERVOUS and MENTAL DISORDERS. Within two miles of the Western and London Midland Regional Railway Stations at Gloucester, the Hospital is easily accessible by rail from London and all parts of the United Kingdom. It is beautifully situated at the foot of the Cotswold Hills, and stands in its own grounds of over 300 acres. Voluntary Patients of both sexes are also received for treatment. Special accommodation is also provided at three villa residences, all of which stand in their own grounds and are entirely separate from the main Hospital. All the most modern methods of treatment including electric shock and prefrontal leucotomy are used.

For Terms, etc., apply to

G. W. T. H. FLEMING, M.R.G.S., L.R.C.P., D.P.M., Physician Superintendent, who may be seen in London by appointment

Telephone: No. 66207 Gloucester 


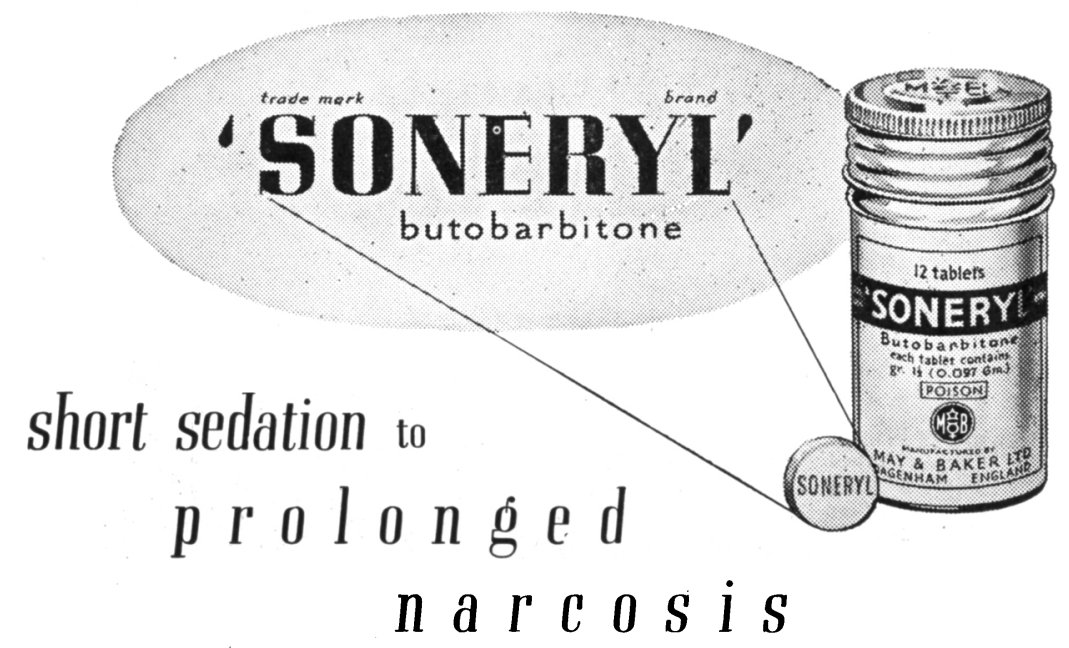

One of the advantages of 'Soneryl' is the ease with which, by graduating the dose, the degree of action may be varied from the mildly sedative to the deeply hypnotic.

This is of particular interest in psychiatric practice for it enables the one drug to be used as a hypnotic in all the mental states from simple anxiety to intractable psychosis. It may be given for long periods with minimal side effects.

Generally 'Soneryl' is given orally in tablets (grains I $\frac{1}{2}$ in each), but for cases in which it is impracticable to give the drug by mouth, suppositories containing three, five or ten grains of 'Soneryl' are available.

Tablets in containers of $12,25,100$, and 500

Suppositories of gr. 3, gr. 5 , and $\mathrm{gr} .10$, in boxes of 5

OUR MEDICAL INFORMATION DIVISION WILL BE PLEASED TO SSEND A COPY OF THE MEDICAL BOOKLET 'M\&B BARBITURATES IN GENERAL PRACTICE' ON REQUEST.

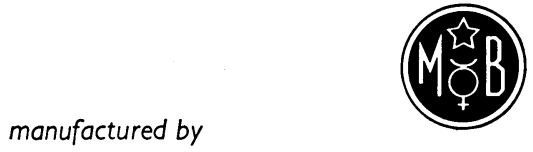

MAY \& BAKER LTD 